\title{
FLUIDEZ TERRITORIAL NAS ÁREAS DE EXPANSÃO DA FRONTEIRA AGRÍCOLA NO PERÍODO DA GLOBALIZAÇÃO*
}

\author{
Daniel Monteiro Huertas**
}

Resumo: No processo de expansão da fronteira agrícola, novas dinâmicas de circulação expressam-se no território brasileiro, muitas das quais portadoras de elementos condizentes com o período técnico-científico-informacional. Partindo do pressuposto de que o avanço da fronteira agrícola age enquanto dinâmica territorial de "soldagem" das regiões Norte e Centro-Oeste ao restante do Brasil, a proposta central deste trabalho reside na análise de uma rede estruturadora de fluxos no "quadrilátero" Manaus - Belém - Distrito Federal/Goiânia - Porto Velho, cuja configuração territorial é permeada de elementos portadores de tecnosfera e psicosfera. Tal rede estrutura a ligação das regiões supracitadas entre si e com as demais zonas do País, proporcionando a integração do mercado nacional, até mesmo dos municípios mais distantes e/ou isolados. Os sistemas de transportes que gravitam em torno da rede sugerida, portanto, elucidam as relações que podem explicar o significado atual da fronteira e revelam as diferentes temporalidades que permitem enxergar quem é hegemônico e quem não é no quadro de correlação de forças da sociedade.

Palavras-chave: fluidez territorial, fronteira agrícola, rede, tecnosfera, psicosfera.

\section{TERRITORIAL FLUIDITY IN AGRICULTURAL EXPANSION AREA IN GLOBALIZATION PERIOD}

\begin{abstract}
In the agricultural border expansion process, new circulation dynamics appear in the Brazilian territory, many of them carrying elements related to the technical-scientific-informational period. Assuming that the advance of agricultural frontier acted as a "welding" territorial dynamic between the North and Center-West regions and the rest of Brazil, the main proposal of this work lies on the analysis of a flow structure network in the Manaus-Belém-Distrito Federal/Goiânia-Porto Velho "quadrilateral", whose territorial shape is permeated by bearer elements of technosphere and psychosphere. This network structures the connection between the regions above and the other parts of the country, enabling the domestic market integration, even the most remote and/or isolated municipalities. The transport system which gravitates around the suggested network, therefore, elucidates the relationships that can explain the meaning of the current frontier and show the different temporalities which enables the understanding of who is and who isn't hegemonic in the society forces.
\end{abstract}

Keywords: territorial fluidity, agricultural border, network, technosphere, psychosphere.

\section{Introdução}

Em sua teoria, Milton Santos dedica ampla discussão à participação de fixos e fluxos na composição do espaço geográfico, sobre o qual se manifesta uma interação mútua entre ambos. Fixos provocam fluxos em função de dados técnicos (geralmente locacionais), mas também em função de dados políticos. Tais prerrogativas, por si só, já são suficientes para elucidar a maneira pela qual o território está sendo usado na rede estruturadora de fluxos proposta neste trabalho, cuja configuração envolveu um processo histórico de ações e objetos que se sucederam de acordo com as peculiaridades de cada período.

\footnotetext{
* A dissertação intitulada Da fachada atlântica ao âmago da hileia: integração nacional e fluidez territorial no processo de expansão da fronteira agrícola, sob orientação da Prof $^{\mathrm{a}}$ Dr $^{\mathrm{a}}$ Mónica Arroyo, foi defendida em 2007.

** Doutorando em Geografia Humana na Universidade de São Paulo e bolsista Fapesp. E-mail: dmh@usp.br.
} 
Nessa trama complexa, reside a introdução de níveis técnicos de transporte mais modernos, com a visão política do grupo que está no poder. A tecnosfera - esse conjunto moderno de fixos e fluxos deles decorrentes - representa a dependência da regulação social em ciência e tecnologia, e "se adapta aos mandamentos da produção e do intercâmbio", enquanto que a psicosfera conjunto de ideias, valores e símbolos - faz parte desse meio geográfico "fornecendo regras à racionalidade ou estimulando o imaginário" (SANTOS, 2004, p. 256).

Com a evolução do meio geográfico, alteram-se os conteúdos enraizados no território, subordinando-se a ele, como o tempo da produção, da circulação, do consumo e da realização de mais-valia. Fluxos e fixos, assim, ganham novos usos segundo a correlação de forças que se estabelece na dinâmica da sociedade, que nem sempre está preocupada com o bemestar da maioria da população e com o atendimento de múltiplas demandas sobretudo em uma sociedade capitalista.

Nesse processo, os sistemas de engenharia participam de uma divisão de trabalho local simples bem como de uma cooperação geograficamente estendida e complexa, passando de poucas a muitas intermediações, com o uso de técnicas cada vez mais estranhas ao grupo. "Se os lugares podem, esquematicamente, permanecer os mesmos, as situações mudam. A história atribui funções diferentes ao mesmo lugar" (SANTOS, 1994, p. 52).

A partir do pressuposto de que 0 avanço da fronteira agrícola age como verdadeira dinâmica territorial de "soldagem" das regiões Norte e Centro-Oeste (correspondentes a $64,12 \%$ do território nacional) ao restante do país, a proposta central deste artigo reside na análise da fluidez territorial material decorrente da reestruturação de alguns subsistemas de movimento situados no bojo desse processo.

Partimos do conceito de fluidez territorial para definir aquela qualidade dos territórios nacionais que permite uma aceleração cada vez maior dos fluxos que o estruturam, a partir da existência de uma base material formada por um conjunto de objetos concebidos, construídos e/ou acondicionados para garantir a realização do movimento. Esses fixos produtivos servem nos diferentes momentos do processo produtivo: na produção propriamente dita (stricto sensu), na distribuição, na troca, no consumo (ARROYO, 2001, p. 105).

Os caminhos, as pontes, os portos, a pavimentação de uma via são elementos cuja capacidade reside exatamente em condicionar (ou ao menos estabelecer) as variáveis intrínsecas à fluidez territorial intensidade, qualidade e natureza dos fluxos - que expressam o poder de definir e limitar a dinâmica dos agentes sociais. Sob essa ótica, pretendemos lançar uma leitura do "quadrilátero" Manaus - Belém - DF/Goiânia - Porto Velho que seja capaz de compreendêlo como uma mediação do concreto pensado, a fim de possibilitar uma análise das novas dinâmicas de circulação no processo de expansão da fronteira agrícola. "Esta, assim, [...] figura na condição de elemento partícipe da formação socioespacial brasileira sobretudo no que diz respeito às dinâmicas territoriais de sua história contemporânea" (HUERTAS, 2009, p. 17).

Quais são os circuitos espaciais produtivos que se movimentam pela rede? De que maneira a intermodalidade está sendo operacionalizada? Como são estabelecidas as 
ações do Estado? Qual o papel da navegação fluvial no universo amazônico? Como as dinâmicas econômicas do Centro-Sul são sobrepostas e estabelecidas, "empurrando" a fronteira para o âmago da hileia? Enfim, o que o quadrilátero representa, de fato, para a coesão territorial da formação socioespacial brasileira?

Milton Santos (2004, p. 263) chama a atenção para o que considera o estudo atual das redes, que deve considerar não apenas a sua constituição técnica qualitativa e quantitativa, mas também a "avaliação das relações que os elementos da rede mantêm com a presente vida social, em todos os seus aspectos". Além da quantidade e da distribuição dos objetos, o uso que thes é dado deve ser parte integrante e relevante da análise das redes.

Ao contextualizar as relações entre o imperativo da fluidez e a constituição das redes - cuja noção de rede global "se impõe nesta fase da história" -, Santos anuncia que o fenômeno da rede se assenta sobre os pilares resultantes da fluidez atual, caracterizados por formas perfeitas universais, normas universais e por uma informação universal. Uma das características do mundo atual é a existência de fluidez para a circulação de ideias, mensagens, produtos ou dinheiro, interessando aos atores hegemônicos. A fluidez contemporânea é baseada nas redes técnicas, que são um dos suportes da competitividade. Daí a busca voraz de ainda mais fluidez, levando à procura de novas técnicas ainda mais eficazes (SANTOS, 2004, p. 274).

Outro aspecto intrínseco ao conceito, a sua relação inseparável com a questão do poder, foi exaustivamente pensado por
Raffestin (1993), que definiu rede como um sistema de linhas que desenham tramas. Para ele, a delimitação de um território, o controle dos pontos e o traçado das vias traduzem as relações de poder, criando relações simétricas e dissimétricas entre os agentes envolvidos na constituição das redes.

Esses sistemas de tessituras, de nós e de redes organizadas hierarquicamente permitem assegurar o controle sobre aquilo que pode ser distribuído, alocado e/ou possuído. Permitem ainda impor e manter uma ou várias ordens. Enfim, permitem realizar a integração e a coesão dos territórios. Esses sistemas constituem o invólucro no qual se originam as relações de poder (RAFFESTIN, 1993, p. 151).

Essa relação com o poder também foi analisada por Santos (2004, p. 263), para quem as redes são, simultaneamente, concentradoras e dispersoras, condutoras de forças centrífugas e centrípetas, germinando uma criação paralela e eficaz de ordem desordem no território, "já que as redes integram e desintegram, destroem velhos recortes espaciais e criam outros".

Constata-se assim a expressão do poder na configuração das redes, capazes de imprimir uma relação territorial contraditória e dialética de acordo com a correlação de forças dos agentes em jogo. Em termos de circulação, o que pode servir para uns não necessariamente serve para outros - e vice-versa. Esperamos corroborar essa ideia com elementos que serão analisados neste trabalho, todos de extrema relevância na constituição da rede estruturadora de fluxos que está sendo proposta e na consequente revelação de pistas que possam ajudar a decifrar o seu uso e a sua inserção na formação socioespacial brasileira, sobretudo sob a ótica da expansão da fronteira agrícola. 


\section{A configuração territorial do "quadrilátero" Manaus - Belém - DF/Goiânia - Porto Velho}

As políticas territoriais implantadas na segunda metade do século $X X$ foram capazes de consolidar o processo de articulação e inserção da Amazônia e do Planalto Central à vida econômica nacional, e as perspectivas de desbravamento e exploração racional de novas áreas alimentavam as ilusões da elite nacional e de alguns setores do capital internacional. Os vultosos investimentos destinados às zonas supracitadas e sua inserção em um plano geopolítico e macroeconômico fizeram com que o regime militar as tratasse como "um grande compromisso histórico", alimentando uma psicosfera - expressa em propaganda oficial, meios de comunicação, selos, livros didáticos etc. - tida como suficientemente eficaz para "rasgar a selva" e expandir a fronteira agrícola.

Assim, entre os anos 1950 e 1990, a configuração da rede estruturadora de fluxos proposta por este trabalho ultrapassa o estágio embrionário de arranjos territoriais regionais com o aporte de novos conteúdos e usos, muitos dos quais relacionados aos pressupostos do meio técnico-científico-informacional. Verifica-se, portanto, outra sucessão de sistemas técnicos, anunciando o novo período que se instala - regido, sobretudo, por mecanismos hegemônicos (ações e objetos) mais ferozes de reprodução e acumulação do capital.

A configuração territorial da rede é composta por 4 troncos e por 4 nodais centrais (Manaus, Belém, Porto Velho e o anel nodal DF/Goiânia) que se entrelaçam com outras linhas de circulação (ramais adjacentes e internos) e com nodais secundários e terciários. É o que propomos chamar de "eixo central" da rede (Mapa 1), um quadrilátero representado pelas linhas de maior densidade de circulação e pelos elos mais dinâmicos em relação à fluidez territorial. Estabelecemos um esquema de classificação hierárquica e funcional de nós, pontos e linhas para facilitar a compreensão da proposta central desta dissertação e três elementos, descritos abaixo, fundamentam a base de sua tipologia:

(1) Infraestrutura logística: composta pelos pontos funcionais (porto organizado, terminal fluvial de uso privado, terminal ferroviário, terminal aeroviário de cargas, centro de distribuição de cargas e terminal fluvial misto) que expressam a hierarquia, a matriz origem/destino e a densidade dos fluxos. De modo geral, situam-se em pontos estratégicos de cidades, pois demandam uma série de serviços (banco, despachante, oficina mecânica, posto de combustível, revenda de autopeças, operador logístico, empresa de táxi aéreo, empresa aérea comercial regular, etc.) inerentes ao meio urbano;

(2) Polos geradores de tráfego: referentes aos principais pontos emissores e receptores de fluxos, cujo movimento pode ser qualificado e quantificado pela composição do mercado consumidor e das forças produtivas;

(3) Direcionamento dos fluxos: são as linhas que expressam a capacidade de atração da demanda e/ou da oferta, baseadas na localização dos pontos de origem e destino dos excedentes exportáveis e importáveis, seja para o mercado externo ou doméstico (intrarregional ou extrarregional). As possibilidades de utilização da intermodalidade são 
fundamentais para determinar essa capacidade.

A seguir, uma breve explicação e descrição dos termos propostos na tipologia da rede:

I) TRoncos: são as linhas que interligam os nodais centrais e expressam a maior densidade de circulação da rede, nas quais o direcionamento dos fluxos é articulado sob a perspectiva de três possíveis variáveis: para os ramais (internos e adjacentes), para as demais regiões do País e para o mercado externo. Compõem a zona de tráfego da rede, ou seja, a área de influência direta do "eixo central", abrangendo os municípios por eles cortados e aqueles que deles dependem para o seu acesso. Também determinam a distribuição modal, pois expressam a capacidade de escoamento dos sistemas modais de acordo com as respectivas interferências no sistema viário como um todo.

II) NODAIS: simbolizam a posição dos agentes e expressam as noções de repartição e sobretudo de hierarquização do território. São lugares de poder e de referência, de junções e disjunções. Agregam os principais pontos funcionais, que compõem os maiores pontos de emissão e/ou recepção de fluxos. Por causa da circulação que empreendem, também podem ser considerados verdadeiros pivôs estruturantes de movimento e acabam se confundindo com os polos geradores de tráfego.

a) Nodais centrais: são os principais entroncamentos do sistema, pois constituem pontos de convergência das vias de interpenetração entre a circulação local, regional, nacional e internacional. Agregam e concentram boa parte dos pontos funcionais, emitindo e recebendo fluxos constantes e variados, de grandezas quantitativas e qualitativas diversas.

A localização estratégica e o grau de urbanização dos nodais centrais revelam nítidas vantagens competitivas de fluidez. Em outras palavras, são potenciais polos geradores de tráfego, com uma dotação básica de infraestrutura logística, cujos fluxos dispõem de múltiplas possibilidades de direcionamento. "O conhecimento dos sistemas de engenharia presentes em cada área é, pois, um dado analítico fundamental, instruindo-nos sobre as possibilidades e os limites à ação dos sistemas sociais" (SANTOS, 2005, p. 137-38). Pelos nodais centrais podemos entender a capacidade de ação dos agentes, sobretudo o poder das empresas de pôr as massas em circulação e as possibilidades de encontro entre os circuitos espaciais e os círculos de cooperação, gerando influências sobre a hierarquia urbana.

b) Nodais secundários: rodeiam os polos a maior ou menor distância, associados ou cúmplices, e frequentemente sujeitas ao seu papel secundário.

c) Nodais terciários: constituídos pelos centros urbanos de relativa importância para a circulação local e regional.

III) RAMAIS: constituem os demais vetores de circulação, funcionando como elos de coleta, abastecimento e estruturação dos fluxos que se dirigem ao eixo central da rede ou que dele partem. Alguns se encontram em consolidação, ou seja, foram planejados como grandes "eixos de penetração", mas a situação precária (geralmente ausência de pavimentação e manutenção) restringe e prejudica a fluidez. 
a) Ramais internos: situam-se no interior do perímetro do eixo central, estabelecendo ligações intraestaduais e/ou intrarregionais e dividindo-o em zonas internas de tráfego.

b) Ramais adjacentes: situam-se fora do perímetro do eixo central, mas estão ligados a ele por nodais centrais ou secundários. Geram as principais zonas externas de tráfego, que podem ser amazônicas (em direção ao Acre, Amapá, Roraima e vale dos rios Negro, Solimões, Juruá, Purus e Trombetas) ou de ligação nacional (com as demais regiões do País).

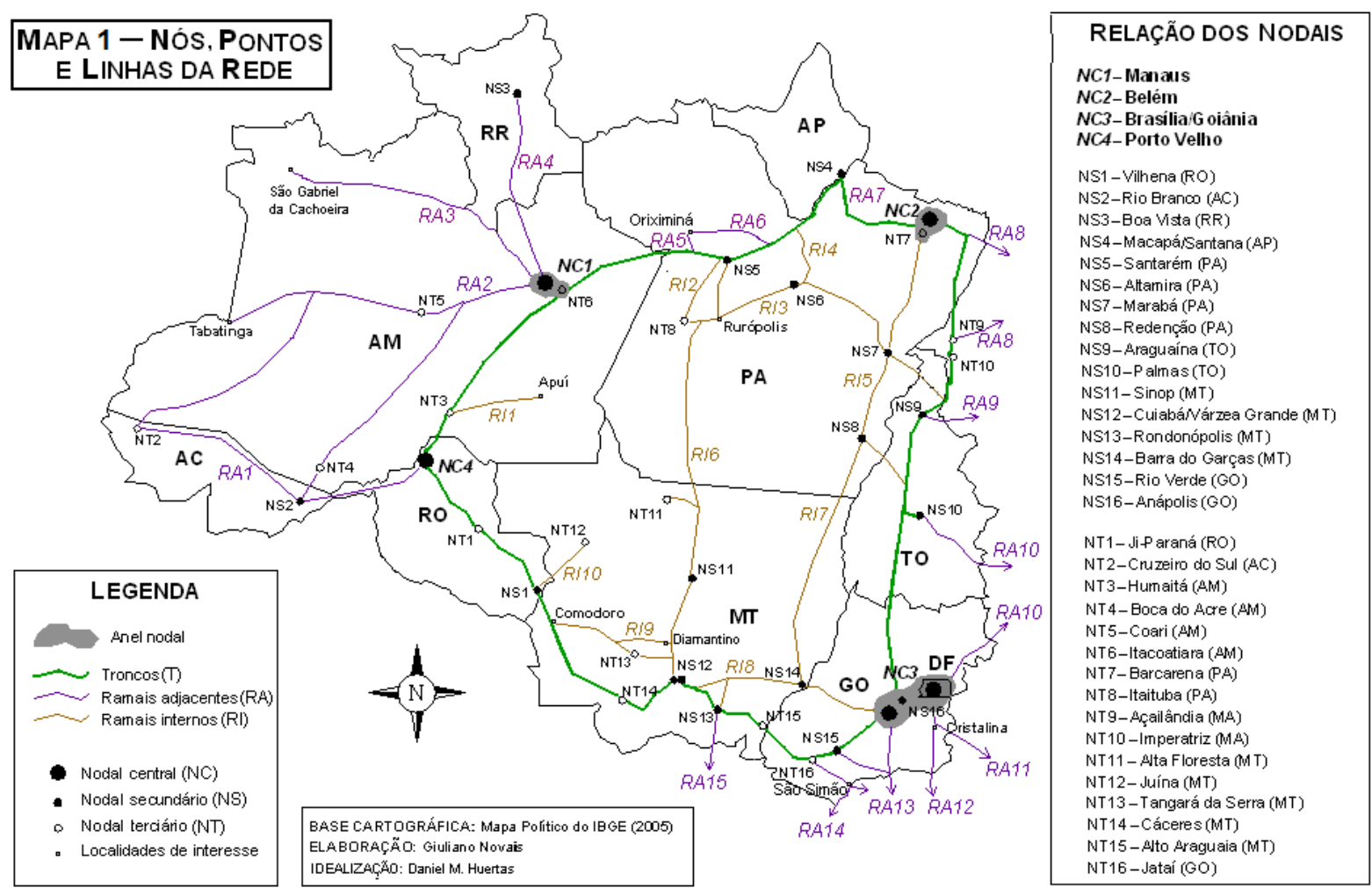

\section{Verticalidades no "deslocamento da fronteira"}

A partir do último quarto do século $X X$, intensas dinâmicas territoriais de deslocamento da fronteira foram estimuladas pela trama espacial exercida por novas e antigas frentes pioneiras, que alavancam e estruturam "espasmos econômicos" que cada vez mais aproximam o Centro-Sul da Amazônia, em movimentos contínuos de apropriação e ocupação de terras ainda sob os desígnios de lógicas pretéritas. Dessa forma, asseguram a integração entre fixos e fluxos, auxiliando no processo de consolidação da rede urbana regional; garantem a expansão dos meios de circulação e as condições da produção e induzem a conexão de subespaços locais e regionais ao mercado nacional, mesmo que esse processo necessariamente não seja extensivo a todos os agentes sociais dos lugares.

Partimos do pressuposto de que o termo fronteira agrícola consolidou-se durante o regime militar, indicando implicitamente uma visão capitalista de 
apropriação, ocupação e uso do espaço. Dessa forma, cabe-nos tentar avaliar o atual estágio do processo de expansão da fronteira, sobretudo no que diz respeito à importância da fluidez territorial nesse contexto - e quais as relações que são estabelecidas com as verticalidades impostas pela rede estruturadora de fluxos.

Em primeiro lugar, cabe uma pergunta: o conceito de frente pioneira ainda é válido? Acreditamos que sim, pois a progressão dessas marchas é um dado extremamente relevante na dinâmica territorial contemporânea de grandes porções da Amazônia (sobretudo no Pará e Mato Grosso), na qual aquela visão de conquista e apropriação do espaço, que tipicamente incide sobre os fundos territoriais, é expressa de forma nítida pelos agentes que procuram se beneficiar, lícita ou ilicitamente, desse processo.

Nas frentes pioneiras o povoamento ainda está em curso, com o cultivo de terras há pouco recobertas, submetidas a avanços constantes de pioneiros, a abertura de novas fazendas e ao contínuo deslocamento migratório, além da posse incompleta da terra em pontos localizados.

O conceito geográfico de frente pioneira foi [...] amplamente revisto para aplicar-se à Amazônia no momento de sua integração à nação [...]. Mesmo que se trate, pela forma, de uma repetição histórica do processo de apropriação territorial, ela vem acompanhada de novas ideologias de conquista, mais voltadas para o crescimento econômico do que para o desenvolvimento. Além disso, a Amazônia propiciaria uma aceleração do fenômeno (DROULERS, 2006, p. 180).
Essas frentes pioneiras, que hoje configuram uma verdadeira mancha quase que contígua, movimentam-se por zonas do país em que ainda não é possível dizer que as condições urbanas e econômicas estejam consolidadas. A presença do Estado é, de certo modo, distante e há um caráter extensivo intrínseco no processo de apropriação das terras, levando a inúmeros conflitos - a situação fundiária dessas áreas é um verdadeiro caos, da qual se origina a expressão "terra de ninguém". Em toda a Amazônia existem 111 milhões de hectares não titulados (ISA, 2005), fato que ainda torna a sua situação fundiária muito confusa e indefinida: $75 \%$ das terras são públicas, das quais $47 \%$ são devolutas, ou seja, áreas em que o governo não deu uma destinação social, favorecendo a grilagem e a retirada ilegal de madeira.

Além disso, lançamos a ideia de que, atualmente, novas frentes são comandadas por frentes antigas, núcleos urbanos que se tornaram centros regionais relevantes ao longo das últimas quatro décadas. Preferimos chamá-los de centros difusores, dada a capacidade de fornecimento de ordens e serviços para os pequenos municípios que gravitam ao seu redor. Assim, estamos diante daquela situação, descrita por Lobato Corrêa (1997), de valorização do território pelas frentes pioneiras, que, a partir de regiões antigas, criaram novas regiões.

Humaitá (AM), Santarém (PA), Itaituba (PA), Altamira (PA), Marabá (PA), Vilhena (RO) e Barra do Garças (MT) são núcleos antigos que passaram por um processo de revigoramento oriundo da valorização econômica de algum produto local ou da abertura de rodovias de penetração. Sinop (MT), Alta Floresta (MT) e 
Redenção (PA) são núcleos novos, criados a partir das políticas de colonização implantadas pelo regime militar.

De modo geral, as condições de fluidez na "mancha pioneira" são extremamente precárias. Levam-se dias, e às vezes semanas, no ir-e-vir de pessoas e mercadorias. Os principais obstáculos são as demoradas travessias de balsas, a ausência de pavimentação em quase todas as rodovias e a generalizada falta de segurança e manutenção das vias. Os motoristas que se aventuram por essas plagas são verdadeiros "guerreiros do volante", sofrendo com a poeira na seca e com os extensos lamaçais no período chuvoso. É um Brasil que se movimenta pela força de vontade de quem se aventurou - ou foi induzido a se aventurar e pela necessidade da sobrevivência.

A simples pavimentação de uma via exerce a capacidade de determinar novas condições de fluidez, redirecionando, na medida do possível, boa parte do tráfego. Sem dúvida, há uma primazia exercida pela circulação na estruturação atual das frentes pioneiras. A pavimentação de uma via nessas zonas inóspitas pode ser comparada a ganchos que tentam capturar áreas de influência. Certamente, aonde chegar o asfalto, uma verticalidade pode se manifestar e novos arranjos tenderão a se estabelecer. É o caso, por exemplo, do vetor Vilhena-Juína (MT), que muito provavelmente sofrerá alterações substanciais com a conclusão do asfaltamento da MT-170 até a cidade matogrossense. O principal acesso a Juína é pela BR-174, por Vilhena, com a qual mantém fortes vínculos, mas o arranjo territorial da porção noroeste do Mato Grosso deve sofrer alterações a médio prazo por causa da nova opção de acesso, via Brasnorte (MT) e Tangará da Serra (MT).

Olhando de um ponto de vista macro, evidencia-se uma tendência, mesmo que a passos lentos, de ligação entre os vetores rodoviários estruturantes da "mancha pioneira". No imperceptível contato entre o cerrado e a floresta amazônica, no centronorte do Mato Grosso, a visibilidade dessa dinâmica é bastante nítida, principalmente por causa do Programa Estradeiro, que será analisado mais adiante. $\mathrm{O}$ mesmo ocorre entre o sul do Pará e o extremo norte do Mato Grosso e entre o eixo da BR-364, em Rondônia, e o Noroeste Mato-Grossense, em direção a Juína, Colniza, Aripuanã e Rondolândia.

Se nos últimos 30 anos as frentes pioneiras na Amazônia ainda eram dispostas como corpos separados e aparentemente desvinculados de qualquer tipo de ordenamento regional, atualmente há uma pressão de diversos agentes para que haja uma verdadeira "costura" dessas regiões, integrando-as ao tecido socioeconômico estadual. Estamos observando, portanto, uma nova dinâmica no avanço do povoamento em direção ao âmago da Amazônia, agora estruturado pelas iminentes ligações de vias secundárias à malha rodoviária nacional, situação necessária para que haja um fortalecimento regional.

Há de se lamentar, entretanto, que tal alinhamento - e por esse motivo falamos em "mancha pioneira", pois a medida em que esse processo é alavancado se intensifica a contiguidade entre novas e antigas frentes pioneiras - esteja privilegiando uma logística que favoreça os grandes empreendimentos produtores de commodities e o escoamento 
para o mercado externo, e debilitando ainda mais os frágeis laços regionais.

Apesar do precário contexto de sua fluidez territorial, pretendemos mostrar que a "mancha pioneira" não se encontra completamente desconectada do território nacional, situação que the confere uma gradativa quebra de seu isolamento geográfico. As frentes pioneiras parecem superar uma etapa caracterizada pelo isolamento total, inserindo-se em dinâmicas espaciais que procuram se ajustar ao tecido socioeconômico intrarregional e nacional. Assim, expressam duas peculiaridades ainda bem visíveis no território nacional: a força das dinâmicas territoriais e a sua constituição inacabada (THÉRY; MELLO, 2005).

A densidade desse processo intensifica a continguidade entre novas e antigas frentes pioneiras e nos autoriza a falar, portanto, em uma mancha. Postada no interior do quadrilátero Porto Velho-Manaus-Belém-DF/Goiânia, esse conjunto de frentes pioneiras mais cedo ou mais tarde estará consolidado do ponto de vista urbano e econômico, reforçado pela ação de verticalidades que se renovam.

Nesse processo, acreditamos que os ramais internos da rede proposta neste trabalho exercerão o papel de captação e direcionamento dos fluxos dessas áreas para os troncos e, consequentemente, para o restante do território nacional. Além disso, os arranjos territoriais no interior do quadrilátero, em consolidação ou ainda embrionários, dependerão, a médio prazo, da combinação entre a estratégia que será adotada pelos diversos agentes envolvidos nesse processo - inclusive do Estado, que a partir dos anos 1990 tem se comportado de modo bastante discreto em relação ao controle e uso do território nessas áreas.

\section{A "mancha pioneira" como sintoma do espaço derivado}

Boa parte dos municípios que compõe a "mancha pioneira" apresenta as maiores taxas de desmatamento do bioma amazônico nos últimos anos - reflexo do desmate desordenado e irracional de áreas para a indústria madeireira e para a prática agropecuária - e um expressivo e perverso processo de especulação fundiária, no qual a grilagem e a venda ilegal de terras (inclusive pela internet) é o seu principal artífice. Consequentemente, os povos da floresta ficam à mercê da ação de grileiros, jagunços, pecuaristas e latifundiários inescrupulosos, que enxergam apenas a perspectiva da expropriação e a avidez do lucro, impondo verticalidades agressivas e alheias aos interesses locais e entrando em conflito com gente da própria da terra.

Encontramo-nos novamente diante daquela situação de espaço derivado, com suas respectivas variáveis, na qual Milton Santos (1978) classifica como específica dos países subdesenvolvidos. A Amazônia, dotada de recursos naturais abundantes, continua sendo tratada por certos agentes econômicos como um espaço periférico, aberto, seletivo, descontínuo e incompletamente organizado.

As frentes pioneiras recentes são espaços abertos, pois estão sendo configurados territorialmente para atender às demandas do mercado externo por commodities. Além da soja, Rondônia e Mato Grosso obtiveram, em 2001, autorização internacional para exportar carne bovina in 
natura. São espaços seletivos, já que as diversas manifestações de modernidade se instalam de maneira pontual, privilegiando as zonas onde a renda da terra possa ser maximizada. São incompletamente organizados, com situação fundiária indefinida e vias de comunicação precárias.

A rarefeita presença humana e os meios rudimentares de sobrevivência de boa parte da população local, desprovida de capital e de qualificação, levam à configuração de um espaço descontínuo. São igualmente fracionados, já que obedientes e polarizados por agentes exógenos, que induzem especializações, ordens e fluxos para onde mais lhes convêm. A débil integração da "mancha pioneira" ao tecido nacional faz com que ela se torne foco constante de movimentos migratórios, tanto de especuladores quanto de camponeses expulsos das zonas rurais mais atrasadas ou até mesmo pela concentração do agronegócio em áreas mais prósperas.

Trata-se dos espaços anunciados como "reservas de valor", justificando a propaganda da Amazônia como o futuro "celeiro do mundo", "[...] os possíveis lugares de realização de uma acumulação primitiva futura devem estar acessíveis ao movimento do capital" (MORAES, 2002, p. 107). Como já dizia Monbeig, cabe analisar até onde essa etapa contemporânea da "mancha pioneira" cuja mobilidade pode, a qualquer tempo, avançar sobre outras áreas da Amazônia, criando novos arranjos territoriais - pode ser explicável pela influência de elementos naturais ou até que ponto corresponde aos mecanismos puramente político-econômicos.

A perenidade do conceito de frente pioneira demonstra a vitalidade dos movimentos ainda em curso no interior do território nacional, embora a sua extensão não tenha contribuído para o equacionamento das mazelas sociais locais, regionais e nacionais. É um espetáculo deprimente ver a floresta e sua imensa riqueza genética serem corroídas gradativamente, levando consigo a ruína daqueles que mais lhes atribuem valor: indígenas, posseiros, caboclos, seringueiros e ribeirinhos, que há séculos mantêm uma relação no mínimo harmoniosa com a hileia.

\section{A navegação fluvial entre o eixo das sucessões e das coexistências}

Toda a bacia amazônica oferece 50 mil km de rios navegáveis na porção brasileira (GEIPOT, 2001), com uma rede hidroviária que totaliza $20.449 \mathrm{~km}$, representando $42,7 \%$ de todas as vias navegáveis do país - para embarcações com deslocamento médio de 100 toneladas, mas ainda cerca de $10 \mathrm{mil} \mathrm{km}$ podem ser navegados por navios com deslocamento médio de 1 mil toneladas ou mais (DOMÍNGUEZ, 2003). Em um universo ditado pelo ritmo das águas, o grau de navegabilidade de um curso d'água também acaba por determinar o ritmo da dinâmica social, pois "há toda uma vida tecida centenariamente em torno da água" sobretudo sob a ótica das relações sociais, "que vão desde a instalação de equipamentos necessários à sobrevivência até a criação de inúmeros mitos" (NOGUEIRA, 1999, p. 83).

Quando se trata de circulação no imenso e complexo emaranhado fluvial amazônico, as temporalidades dos agentes sociais aparecem explicitamente diante dos olhos do observador. Da pesca solitária em uma canoa, empunhando um remo e uma 
tarrafa, ao navio transatlântico que parece "rasgar" os rios, os eventos se sucedem e convivem segundo múltiplas manifestações no território, revelando sucessões e coexistências na divisão territorial do trabalho. "Constatamos, de um lado, uma assincronia na sequência temporal dos diversos vetores e, de outro lado, a sincronia de sua existência comum, num dado momento. O entendimento dos lugares, em sua situação atual e em sua evolução, depende da consideração do eixo das sucessões e do eixo das coexistências" (SANTOS, 2004, p. 159).

Ao se referir aos rios de menor porte da Bacia Amazônica, Domínguez (2003, p. 169) destaca o papel relevante desses cursos d'água, "pois se constituem na única possibilidade de acesso a portos remotos ou a áreas inundáveis onde a construção de estradas não é possível".

Com um padrão de povoamento linear, as sociedades originárias da região construíram, em grande parte, todas as suas relações de comunicação e transporte utilizando o rio como via. A extensão lateral das várzeas, associada à enorme variação do regime fluvial, já dava aos rios a vantagem para a circulação de pessoas e produtos (NOGUEIRA, 1999, p. 71).

Diante de tamanha expressão, a navegação interior adquire na Amazônia dimensões territoriais impensáveis para a era do automóvel, não apenas em relação às distâncias percorridas, à velocidade lenta e à função socioeconômica que exerce, mas sobretudo no que diz respeito ao imaginário coletivo das populações envolvidas - o que Reinaldo Costa (2004) chamou de forte presença das "forças telúricas":
O movimento das águas é um dos pontos vitais e característicos do domínio amazônico. Nisso permeiam as potencialidades de conhecer a natureza e extrair dela elementos para o seu sustento, para a reprodução social em cada espaço florestado, campestre e ribeirinho (COSTA, 2004, p. 85).

Silveira Costa (1997, p. 17), em uma análise voltada para o lado mais comercial e estratégico, vê a navegação interior como assunto de Estado, com "características polivalentes", cujos efeitos refletem diretamente no desenvolvimento da nação, obtendo a integração e o crescimento de regiões mais afastadas: "[...] além de ser um instrumento de transporte econômico, é, pela sua penetração, fator estimulante para 0 implemento de atividades industriais, comerciais e turísticas nas cidades e vilas beneficiadas."

O autor ainda destaca o estímulo ao processo de urbanização de vilas e cidades ribeirinhas da Amazônia, promovendo a fixação do homem no interior e facilitando o transporte intermodal. "Não é por outra razão que, por lá, a rua é o rio" (1997, p. 24). Para Carreteiro (1987, p. 143), a via navegável ainda assume uma "função exploradora" na Amazônia: "[...] a hidrovia é uma realidade. Através dela o homem penetrou na floresta, e ainda é o barco o principal meio de transporte do homem amazonense."

Além do transporte de passageiros, outro elemento que evidencia o papel social da navegação regional é a circulação de mercadorias de gênero alimentício, principalmente hortifrutigranjeiros, carne congelada (bovina, suína e frango) e farinha de mandioca e de trigo. Mesmo diante desse contexto, há um relativo descaso governamental em relação à atividade. "Acho 
que estão dando prioridade à infraestrutura do carregamento de soja", disse o armador do barco motor "Coração de Mãe", que opera regularmente na rota Manaus-Porto Velho-Manaus.

No convés da embarcação, havia $\mathrm{R} \$$ 35 mil em caixas de alho, batata, pimentão, tomate e cebola, oriundos de São Paulo, Minas Gerais e Goiás com destino a pequenos comerciantes e atravessadores da capital amazonense. Em Santarém, o barco rumo a Oriximiná, no norte do Pará, levava sacos de cebola, cachos de banana e caixas de repolho, tomate e laranja, produtos que cruzaram o país em rios e rodovias para abastecer áreas de pouca ou inexistente atividade agrícola.

A mobilidade da população nessas longas viagens também reflete um pouco do "caráter itinerante" de alguns setores da população brasileira. Um grupo de mineiros de Belo Horizonte portava caixas com queijo provolone defumado para degustação nos bares e restaurantes de Manaus. A expectativa era a de conquistar clientes para futuras remessas. Um paranaense de Marechal Cândido Rondon levava um carregamento de sacos de farinha de trigo, enquanto um casal - ele de Almenara (MG), ela de Santa Inês (MA) - e o filho pequeno rumavam para uma nova vida em Boa Vista, depois de alguns anos em Ariquemes (RO). Outro passageiro voltava de férias de sua terra natal, Cruzeiro do Sul (AC). O seu "vizinho de rede", aposentado e morando no Rio de Janeiro, fazia o caminho inverso: passar férias na sua terra natal.

Mais do que mercadorias, os barcos regionais carregam também estórias de vida e expectativas de quem aposta na Amazônia como a esperança de uma vida melhor, de um mercado ainda em estágio potencial ou de uma oportunidade para agarrar o tão sonhado lote de terra. Em sua essência, são objetos flutuantes portadores de eventos com grande potencial de imbricamento local, contribuindo para a germinação de regras localmente formuladas e reformuladas e para o domínio das forças centrípetas. "Alcançar as comunidades alojadas às margens dos rios é tarefa de todos, seja do poder público ou do setor privado, visando oferecer o mínimo de dignidade aos cidadãos ribeirinhos", disse o antropólogo Dimitri Sávio, da Fundação Amazonas Legal ${ }^{1}$.

Contribuirão para o abastecimento das mercearias e dos pequenos mercados, e não para os estoques dos grandes supermercados; levam e trazem objetos de grande utilidade e valor para uma parcela considerável do tecido social local, e não apenas mercadorias que em pouca medida o beneficiará; levam e trazem saudades, sonhos e expectativas de entes queridos, parentes e conhecidos, fortalecendo os laços locais de solidariedade e união. Às grandes empresas de navegação, ficam reservadas os produtos de alto valor agregado e as commodities agrominerais que muitas vezes não fazem o menor sentido àquela realidade social, impondo as verticalidades condizentes apenas com os atores hegemônicos.

\section{Para o Estado, a logística é concebida como estratégia de organização territorial}

O conhecimento da visão que os representantes do poder público estadual têm desenvolvido acerca da logística de transportes de seus respectivos Estados é um dado fundamental em relação à rede 
estruturadora de fluxos proposta neste trabalho. Não podemos perder de vista que os investimentos em infraestrutura são canalizados e direcionados por políticas públicas, cujos interesses nem sempre estão em consonância com as demandas da sociedade como um todo, além de relativa desconexão com um projeto nacional que pense o país de maneira contínua, coesa e articulada.

Os trabalhos de campo realizados em quase todos os Estados das regiões CentroOeste e Norte possibilitaram contatos preciosos com técnicos dos órgãos públicos responsáveis pela elaboração, execução e fiscalização das obras de infraestrutura. As principais ideias, estratégias e argumentos incluídos nos PPAs elaborados para o quadriênio 2004-07 e expostos pelos entrevistados são capazes de expor a visão do poder público para o setor de transportes. O nosso objetivo, com isso, é nos aproximarmos ainda mais da configuração e do papel regional da rede estruturadora de fluxos, tentando relacionar e analisar os projetos que possam manter vínculos infraestruturais com os seus nós, pontos e linhas.

\footnotetext{
Diante do recente quadro de investimentos estaduais e federais em infraestrutura, podemos afirmar que, de um modo geral, os projetos em rodovias, ferrovias e hidrovias têm buscado atrair o capital privado, sobretudo os grandes empreendimentos voltados para o mercado externo. Notam-se, desse modo, estratégias preocupadas com as ligações portuárias mais eficientes e baratas, em detrimento de conexões intraestaduais e intrarregionais, as únicas capazes de efetivamente abarcar todo o território de um Estado ou de uma região.
}

Uma verdadeira "onda exportadora" tomou conta do empresariado nacional e das políticas públicas em geral desde a abertura econômica dos anos 1990, como se o único caminho possível para o desenvolvimento do país fosse germinar ideias e desenhar projetos voltados para os mercados consumidores alheios. Parece que há um pacto arquitetado entre os círculos decisórios, destinados a assinar uma espécie de "destino manifesto exportador" que acaba contribuindo indiretamente para congelar algumas parcelas das forças produtivas e outras capacidades potenciais, em vários ramos da economia, que poderiam vir a se realizar no Brasil.

Com a abertura econômica dos anos 90, surgem novas alternativas de articulação econômica regional, possibilitando aos distintos sistemas produtivos internos uma ligação direta com o exterior e enfraquecendo, portanto, a amarração territorial presidida pela lógica de estruturação do mercado interno (IPEA et al., 2001, p. 118).

Como historicamente o Brasil vem incrementando a sua capacidade de se projetar perante o sistema internacional de trocas como um grande fornecedor de produtos com baixo ou nenhum valor agregado (commodities) para os países do chamado Primeiro Mundo - e, mais recentemente, para a China -, há uma pressão de setores produtivos privados e da mídia para que o território nacional seja adequado a responder às novas "demandas globalizadas".

No caminho entre as áreas produtoras e os portos há imensas porções do território nacional que direta e indiretamente serão contempladas com a circulação de fixos e fluxos, mas não foram 
arquitetadas políticas simultâneas e correlatas que procurem "agregar valor territorial" à produção. Articulação e formação de cadeias regionais, arranjos produtivos locais, fortalecimento de cooperativas e linhas intrarregionais de circulação invariavelmente são tratadas pelos órgãos decisórios como projetos de expressão econômica reduzida, cujo impacto na contabilidade nacional não atrai divisas e não gera impostos.

Para o setor privado, quem tem de suportar o pesado ônus de "alterar o mapa logístico do Brasil" ou de "destravar os gargalos logísticos" é o Estado, cuja capacidade de investimento está bem aquém do se espera, incompatível com o crescimento exacerbado da corrente de comércio e dos consequentes fluxos de mercadorias que cruzam as fronteiras nacionais, agora muito mais porosas e permeáveis.

A psicosfera gerada em torno do setor de transportes - o chamado "custo Brasil" foi uma expressão muito utilizada nos anos 1990 sempre a favor do grande capital - fomenta no imaginário coletivo a impressão de que a maioria da população se movimenta pelo país em busca de seus inúmeros atrativos culturais e naturais, assim como se a produção local e regional percorresse todos os quadrantes do território nacional em busca dos mercados.

Tomado por essa mentalidade, o poder público elabora a sua própria psicosfera, intimamente relacionada aos grandiosos projetos que têm como objetivo maior a exportação de mercadorias. Eis algumas das expressões que alimentam esse discurso:
- "O novo eixo logístico do país" (material institucional do governo do Tocantins);

- "Ferrovia Norte-Sul: acelerando o crescimento do Brasil, do Tocantins, da sua empresa e de seus investimentos" (ibidem);

- "Goiás acessa o mar: alternativas para melhorar os corredores hidroferroviários" (material institucional do governo de Goiás);

- "Hidrovias Tocantins e Araguaia: o caminho natural para o desenvolvimento" (material institucional da Administração das Hidrovias do Tocantins e Araguaia/Ahitar);

- "Transporte intermodal: solução para o escoamento da produção" (material institucional da Sociedade de Portos e Hidrovias do Estado de Rondônia/SOPH);

- "Terminal do Espadarte: o grande projeto portuário que vai expandir e melhorar a exportação de minérios e grãos do Brasil para o mundo" (material institucional da Companhia Docas do Pará/CDP);

- "Porto de Santarém: a melhor e mais barata opção de escoamento dos grãos do Centro-Oeste brasileiro" (ibidem);

- "Complexo de Vila do Conde: um porto de vital importância para a economia brasileira, por onde nossas riquezas brutas escoam e se transformam em divisas" (ibidem);

- "Terminal do Outeiro: o caminho alternativo que levará nossos produtos para o mercado externo com vantagens locacionais e 
custos cada vez mais competitivos" (ibidem);

- "Destravar é um verbo novo que entra na semântica de 2007. Mato Grosso tem motivos para entender assim as possibilidades anunciadas pelo Programa de Aceleração do Crescimento [...]" (Revista RDM, ano VIII, n. 160, jan, 2007, p. 20).

O Estado nacional, em suas esferas estadual e federal, entronizou a logística como elemento primordial para a estruturação e organização do território. Mas como grande parte da receita brasileira é realizada no exterior, a logística configurada no território nacional não está direcionada prioritariamente para o mercado interno. Soma-se a isso o fato de que os agentes políticos e econômicos da vida nacional não desfrutam de qualquer instrumento de interferência sobre a composição dos preços dos principais produtos da pauta brasileira de exportações (commodities agropecuárias e minerais), estabelecidos pelo mercado internacional nas praças financeiras do Hemisfério Norte e historicamente instáveis, com registro de oscilações abruptas e repentinas.

Como resultado final, fica a triste constatação de que a grande maioria da população não é beneficiada por esse "imperativo territorial", já que os agentes com menor potencial técnico e financeiro, tidos como "lentos e opacos" (SANTOS; SILVEIRA, 2001), frequentemente são deixados em segundo plano pelas estatísticas e também pelas políticas públicas.

Assim, o círculo vicioso é mantido, seja por conveniência e inércia política, seja por influências ocultas (algumas nem tão ocultas assim...). Domesticamente, fluxos, decisões e renda são orientados e reorientados para a Região Concentrada. No sistema internacional de trocas, o país reforça a sua condição periférica na economia-mundo, exportando commodities, capitais (royalties, juros e lucros) e produtos industrializados de baixo e médio valor agregado, e importando tecnologia, produtos industrializados de alto valor agregado (sobretudo bens de capital) e capitais (empréstimos e investimentos produtivos e especulativos).

Não se observa um questionamento mínimo sobre o mercado interno, se as linhas de circulação do país estão sendo devidamente arquitetadas e coordenadas para proporcionar seu fortalecimento. O que importa, no discurso atual, são as saídas para o estrangeiro...

\section{Considerações finais}

A pesquisa nos levou a propor, entre outras, as seguintes considerações:

(1) A expansão da fronteira agrícola ainda é um imperativo territorial da história recente do Brasil, cujo processo em vigência avança cada vez mais em direção ao âmago da hileia. Essa evidência anuncia um iminente esgotamento das possibilidades de abertura de novas áreas à exploração agropecuária no domínio dos cerrados, que assim praticamente consolida a sua posição de base de ocupação territorial da Amazônia.

(2) As frentes pioneiras continuam emergindo, mas agora inseridas em uma dinâmica de "costura" regional que acabou por 
configurar o que estamos propondo chamar de "mancha pioneira", na qual alguns centros urbanos difusores e eixos rodoviários situados no interior do "quadrilátero" (centro-sul do Pará, centro-norte do Mato Grosso e sudeste do Amazonas) funcionam como seus elementos estruturantes.

(3) Esse subsistema de movimento é um indicativo do uso do território, já que abrange todas as manifestações da técnica e a consequente ação concreta de cada ator no período atual. Em seu eixo central (troncos e nodais centrais), verifica-se o predomínio das técnicas hegemônicas, dando um caráter de rigidez aos fenômenos técnicos e às normas. Nos ramais adjacentes amazônicos, as variáveis determinantes do período técnicocientífico-informacional não são tão presentes e a mobilidade material e imaterial não é totalmente controlada e/ou prevista a partir de um centro de decisão.

(4) Acreditamos que o "eixo central" da rede desempenha um papel de soldagem de espaços regionais ao âmbito nacional, evidenciado pelo sentido econômico da ligação e formação de áreas de produção (pecuária, grãos etc.) e intensificação do fluxo de mercadorias. As cidades da Amazônia desempenham um papel fundamental na articulação produtiva regional, pois um amplo leque de estratégias territoriais - composto por áreas protegidas em macroescala - não permite seu povoamento pleno. Consequentemente, verifica-se uma indução à concentração espacial do tecido socioeconômico que põe frente a frente estratégias logísticas díspares e não complementares, muitas vezes incapazes de expressar a complexidade do uso do território na Amazônia. Aos principais centros urbanos de Mato Grosso e Goiás, parece que coube perfeitamente o papel de "plataforma de ocupação" da hileia, uma espécie de "plano intermediário logístico" entre a Região Concentrada e a Região Norte - condição que contribuiu decisivamente para a ruptura do padrão flúvio-linear da organização espacial da Amazônia e do modelo dendrítico de sua rede urbana, embora na Amazônia Oriental este ainda se encontre muito presente.

(5) O eixo Distrito Federal/Goiânia compõe um "cordão espacial" de grande monta à arquitetura logística nacional - e alguns argumentos reforçam essa prerrogativa e dão força à ideia, que sob o nosso ponto de vista já está em pleno processo de maturação. A fronteira agrícola mantém o caráter periférico das regiões Norte e Centro-Oeste no contexto nacional e por si só já não apresenta mais condições de explicar os arranjos territoriais em curso nessas zonas do País. A força de suas dinâmicas, entretanto, ainda é capaz de evidenciar uma boa parte das possibilidades técnicas e políticas que transformam o território nacional no atual período histórico, aproximando o Centro-Sul da Amazônia e deslocando a fronteira para o interior da floresta.

\section{Nota}

Extraído da Revista Panorama Atual (editada pela CNT, n. 113, jan, 2005, p. 31). 


\section{Referências bibliográficas}

ARROYO, M. M. Território nacional e mercado externo: uma leitura do Brasil na virada do século XX. Tese (Doutorado) - Departamento de Geografia, Faculdade de Filosofia, Letras e Ciências Humanas, Universidade de São Paulo, São Paulo, 2001.

\section{CARRETEIRO, R. P. A navegação na} Amazônia. Manaus: Calderaro, 1987.

CÔRREA, R. L. Trajetórias geográficas. Rio de Janeiro: Bertrand Brasil, 1997.

COSTA, L. S. S. As hidrovias interiores no Brasil. Rio de Janeiro: Serviço de Documentação da Marinha, 1997.

COSTA, R. C. Xingu-Transamazônica: linha de queda, territorialidades e conflitos. Tese (Doutorado) - Departamento de Geografia, Faculdade de Filosofia, Letras e Ciências Humanas, Universidade de São Paulo, São Paulo, 2004.

DOMÍNGUEZ, C. Importância dos rios no sistema de transportes da Amazônia. In: ARAGÓN, L. E.; CLÜSENER-GODT, M. Problemática do uso local e global da água da Amazônia. Belém: NAEA, 2003. p. 161-190.

DROULERS, M. Estudos sobre a Amazônia: a posteridade de Pierre Monbeig. In: SAlgueIRO, H. A. (Org.). Pierre Monbeig e a Geografia Humana Brasileira. Bauru: Edusc, 2006. p.171-190.

EMPRESA BRASILEIRA DE PLANEJAMENTO DE TRANSPORTES (Geipot). A reforma portuária brasileira. Brasília: Geipot, 2001.

HUERTAS, D. M. Da fachada atlântica à imensidão amazônica: fronteira agrícola e integração territorial. São

Paulo: Annablume, 2009.

INSTITUTO DE PESQUISA ECONÔMICA

APLICADA (IPEA) et al. Série caracterização e tendências da rede urbana do Brasil. Brasília: Ipea, 2001, v. 1.

INSTITUTO SOCIOAMBIENTAL (ISA). Desafios e sustentabilidade socioambiental ao longo do eixo Cuiabá - Santarém. Relatório final do Encontro BR-163 Sustentável. Sinop, 2004.

MORAES, A. C. R. Território e história no Brasil. São Paulo: Hucitec, 2002.

NOGUEIRA, R. J. B. Caminhos que marcham: o transporte fluvial na Amazônia. Terra das Águas, Revista do Núcleo de Estudos Amazônicos da UnB, Brasília, v.1, n.2, 1999, p.70-83.

RAFFESTIN, C. Por uma geografia do poder. São Paulo: Ática, 1993[1980].

SANTOS, M. A urbanização brasileira. 5. ed. São Paulo: Edusp, 2005[1993].

A natureza do espaço: técnica e tempo, razão e emoção. 4. ed. São Paulo: Edusp, 2004[1996].

Metamorfoses do espaço habitado. 3. ed. São Paulo: Hucitec, 1994[1988].

. O trabalho do geógrafo no Terceiro Mundo. São Paulo: Hucitec, 1978.

; SILVEIRA, M. L. O Brasil: território e sociedade no início do século XXI.

3. ed. Rio de Janeiro: Record, 2001.

THÉRY, H.; MELLO, N. A. Atlas do Brasil: disparidades e dinâmicas do território. São Paulo: Edusp, 2005. 